\title{
Production of MLM-Type structured lipids from fish oil catalyzed by Thermomyces lanuginosus lipase
}

\author{
Joab Sousa ${ }^{*}$, Arthur Souza, Alexandre Torres, Denise Freire \\ From 5th Congress of the Brazilian Biotechnology Society (SBBIOTEC) \\ Florianópolis, Brazil. 10-14 November 2013
}

\section{Background}

Lipases are powerful tools for the syntheses of structured lipids (SL) which are triacylglycerols (TAG) having particular fatty acid residues at specific positions. The production of TAG with medium chain fatty acids (MCFA), in positions $s n-1$ and $s n-3$, and a long-chain fatty acid (LCFA), in the internal position, has recently increased due to its nutritional interest in applications as reduced calorie fats [1].

Molecular structure of TAGs influences the fatty metabolism in organisms. Consequently, it is possible to control and improve the nutritional and pharmaceutical properties of TAGs with a correct design of SL chemical structure. The dietary reference intake of long-chain n-3 PUFA is based on current intake of a healthy population, and consists of 135-270 mg a day of EPA+DHA [2]. The intake of reduced levels of long-chain $n-3$ fatty acids have negative consequences in human health, and might occur relatively frequently in situations of irregular fish consumption.

So, the aim this work is to produce food oil with a low calorific value, with high content of eicosapentaenoic (EPA) and docosapentaenoic (DHA) acids from fish oil, which is useful for people who suffer from obesity or metabolic disorders caused by lack of such polyunsaturated fatty acids (PUFA) in the metabolism.

\section{Methods}

Acidolysis reaction

A fixed amount of Thermomyces lanuginosus immobilized (Lipozyme TL IM) and free lipase (Lipozyme TL 100L) ( $2 \% \mathrm{wt} \%$ of total substrates) was used for the acidolysis reactions that were performed at $40^{\circ} \mathrm{C}$, in solvent-free media, at a molar ratio 1:2 (fish oil:free fatty acid) in thermostated-capped cylindrical glass vessels under magnetic stirring, for $24 \mathrm{~h}$.

\section{Analysis of products}

The product mixture was separated by thin-layer chromatography (TLC) on silica gel plates and developed with nhexane/ethyl ether/acetic acid (70:30:1). After this procedure, TLC plates were air-dried and sprayed with $0.2 \%(\mathrm{w} /$ v) 2,7-dichlorofluorescein in $95 \%$ ethanol and the bands were visualized by ultraviolet light. The various groups of compounds (triacylglycerols, free fatty acids, diacylglycerols and monoacylglycerols) were identified by comparison with standards. The bands corresponding to TAG were scraped from TLC plates methylated and analyzed [3].

\section{Results}

It was possible to obtain TAG of MLM type by acidolysis of fish oil with caprylic acid. Higher incorporations of caprylic acid (50\%) into the TAG in these conditions were attained with both forms of lipase. The oils generated in this process provide about 88 to $92 \mathrm{mg}$ of the mixture of EPA+DHA per g oil using free (TL 100L) and immobilized (TL IM) forms of Thermomyces lanuginosus lipase. This amount was adequate for daily intake of EPA + DHA besides generating oil with low calorie.

\section{Conclusions}

The both forms tested of Thermomyces lanuginosus lipase was able to catalyze the incorporation of caprylic acid into fish oil.

The oil generated is process could be used as a dietary supplement for specific clinical situations, once it has been possible to produce of nutritionally valued oils, rich in EPA and DHA with low calorie.

\section{Acknowledgements \\ The authors are grateful to financial support received from FAPERJ, CNPq and CAPES (Brazil) is greatly acknowledged.}

Published: 1 October 2014 


\section{References}

1. Xu X: Production of specific-structured triacylglycerols by lipasecatalyzed reactions: a review. Eur J Lipid Sci Technol 2000, 102:287-303.

2. Institute of Medicine: Dietary Reference Intakes for Energy and

Macronutrients. Washington, DC: National Academy Press; 2005.

3. Lepage G, Roy CC: Direct transesterification of all classes of lipids in a one-step reaction. J Lipid Res 1986, 27:114-120.

doi:10.1186/1753-6561-8-S4-P44

Cite this article as: Sousa et al:: Production of MLM-Type structured lipids from fish oil catalyzed by Thermomyces lanuginosus lipase. BMC Proceedings 2014 8(Suppl 4):P44.

Submit your next manuscript to BioMed Central and take full advantage of:

- Convenient online submission

- Thorough peer review

- No space constraints or color figure charges

- Immediate publication on acceptance

- Inclusion in PubMed, CAS, Scopus and Google Scholar

- Research which is freely available for redistribution

Submit your manuscript at www.biomedcentral.com/submit 